\title{
DETERMINANTES DO GERENCIAMENTO DE RESULTADOS EM OFERTAS PÚBLICAS INICIAIS (IPOS) DE AÇÕES NO MERCADO DE CAPITAIS BRASILEIRO
}

\section{DETERMINANTS OF EARNING MANAGEMENT AT INITIAL PUBLIC OFFERINGS (IPOS) IN BRAZILIAN STOCK MARKETS}

\section{DETERMINANTES DE LA GESTIÓN DE GANANCIAS EN LAS OFERTAS PÚBLICAS INICIALES (OPI) EN LOS MERCADOS BURSÁTILES BRASILEÑOS}

Recebido em: 27-09-2017

Avaliado em: 11-04-2020

Reformulado em: 11-05-2020

Aceito para publicação em: 17-06-2020

Publicado em: 02-09-2020

Editor Responsável: Moacir M. Rodrigues Junior
Paulo Henrique Fonseca de Melo ${ }^{1}$

Wagner Moura Lamonier ${ }^{2}$

\section{RESUMO}

Uma oferta pública inicial de ações (IPO) constitui um evento de transformação na organização. A entrada de novos sócios via mercado significa uma mudança de paradigma na gestão e na cultura da empresa. Ao abrir o capital as empresas têm acesso a elevado montante de recursos e proporcionam a seus investidores em private equity a possibilidade de diversificar seus investimentos. Foram avaliados 92 IPOs ocorridos no mercado de capitais brasileiro nos últimos anos. As acumulações discricionárias são positivas e relevantes no período que engloba os três anos ao redor da data do IPO (anos -1, 0 e +1 ) indicando a ocorrência de Gerenciamento de Resultados (GR) nesses processos. Quanto aos condicionantes para a prática do gerenciamento de resultados, pôde se inferir com os resultados da pesquisa que há indícios estatisticamente significativos de que variáveis como a Fase do IPO, se se trata de um período "Quente", se são empresas do ISE, se é uma SEO, se tem Governança Corporativa diferenciada, Crescimento da firma, Desempenho, Capital de Giro, Tamanho e PIB se caracterizam como condicionantes do gerenciamento de resultados no contexto dos IPOs no mercado de capitais brasileiro. Essas conclusões se baseiam nos resultados dos modelos a partir da análise dos níveis de accruals discricionários assumidos pelas empresas ao longo dos períodos pré e pós IPOs analisados.

Palavras Chave: Gerenciamento de Resultados, Accruals, Determinantes do GR.

\section{ABSTRACT}

An initial public offering (IPO) is a transformation event in the organization. The entry of new members through the market means a paradigm shift in the management and company culture. To go public companies have access to large amounts of resources and provide their private equity investors the opportunity to diversify their investments. 92 recent IPOs in the Brazilian capital markets were evaluated. It was observed that on average discretionary accruals are positive during the period that

\footnotetext{
${ }^{1}$ Mestre em Ciências Contábeis pela Universidade Federal de Minas Gerais (UFMG); E-mail: phfons@gmail.com

${ }^{2}$ Doutor em Economia pela Universidade Federal de Viçosa (UFV); Professor do Programa de Pós-Graduação em Controladoria e Contabilidade da Universidade Federal de Minas Gerais (UFMG); E-mail: wagner@ face.ufmg.br
} 
encompasses the three years around the IPO date (year -1, 0 and +1 ). As for the determinants for the practice of earnings management (EM), it can be inferred that there is evidence that the variables IPO Stage, Hot Markets, ISE, SEO, GC, Growth, Performance, Working Capital, size and GDP are characterized as management constraints of results in the context of IPOs pointing to higher or lower levels of discretionary accruals made by companies. These conclusions are based on the results of the models based on the analysis of the levels of discretionary accruals assumed by the companies over the periods pre and post IPOs analysed.

Keywords: Earnings Management, Accruals, EM Determinants.

\section{RESUMEN}

Una oferta pública inicial (IPO) es un evento de transformación en la organización. La entrada de nuevos miembros a través del mercado significa un cambio de paradigma en la gestión y cultura de la empresa. Para ir las empresas públicas tienen acceso a grandes cantidades de recursos y proporcionar a sus inversionistas de capital privado la oportunidad de diversificar sus inversiones. Se evaluaron 92 IPOs recientes en los mercados de capitales brasileños. Se observó que en promedio los devengos discrecionales son positivos durante el período que abarca los tres años alrededor de la fecha de la OPI (año -1, 0 y +1). En cuanto a los determinantes para la práctica de la gestión de ganancias (GG), se puede inferir que hay evidencia de que las variables IPO Etapa, Hot Markets, ISE, SEO, GC, crecimiento, rendimiento, capital de trabajo, tamaño y GDP se caracterizan como las restricciones de gestión de los resultados en el contexto de las OPIs que apuntan a niveles más altos o más bajos de acumulaciones discrecionales hechas por las empresas. Estas conclusiones se basan en los resultados de los modelos basados en el análisis de los niveles de acumulación discrecional asumidos por las empresas durante los períodos previos y posteriores a las OPIs analizados.

Palabras clave: Gestión de ganancias, Acumulaciones, Determinantes de GG.

\section{INTRODUÇÃO}

Uma Oferta Pública Inicial de ações (IPO) constitui um evento de transformação na organização. A entrada de novos sócios via mercado significa uma mudança de paradigma na gestão e na cultura das firmas. Tornando-se uma empresa de capital aberto, a mesma precisará atender a novas exigências o que acarretará novos conjuntos de competências da administração e dos funcionários, controles adicionais e mudanças nos negócios. Preparar-se para atender a estas novas exigências é de suma importância para que haja uma transição bem sucedida e também para que se reduzam as surpresas após o IPO (BM\&FBovespa, 2014).

Através da abertura de capital, as empresas procuram obter recursos em condições mais atraentes nos mercados para financiamento de seus projetos. Ao abrir o capital as empresas têm acesso a elevado montante de recursos e proporcionam a seus investidores em private equity a possibilidade de diversificar seus investimentos (Ronen \& Yaari, 2008; Berk \& Demarzo, 2009).

O interesse de investidores, analistas e acadêmicos sobre o movimento de abertura de capital cresce à medida que o mercado acionário no país amadurece e se profissionaliza permeado pelos conceitos de Governança Corporativa e transparência. Sendo assim, diante da ascensão do número de IPOs torna-se importante estudar os fatores que fundamentam este mercado, bem como o desempenho destas empresas no mercado acionário.

Entretanto, a Regulamentação Contábil, em determinadas situações é significativamente flexível, permitindo que os gestores utilizem a sua discricionariedade na definição dos critérios contábeis que serão adotados, prejudicando assim a qualidade da informação contábil divulgada ao usuário externo, dado o conflito de interesses existente entre estes stakeholders. Ou seja, o gerenciamento de resultados (GR) não quer dizer fraude contábil. Envolve a flexibilidade das normas e princípios contábeis, que permitem certa discricionariedade para os gestores. Consequentemente, 
os gestores podem utilizar essa lacuna proporcionada pela flexibilidade para efetuar suas escolhas contábeis (accounting choices). Essas escolhas podem não retratar a realidade dos negócios, mas sim, os incentivos que os levam a reportar determinado resultado no período.

Conforme apontam Roosenboom et al. (2003), no momento da Oferta Pública Inicial, os gestores conhecem melhor a realidade futura da empresa em relação aos seus fluxos de caixa vindouros e suas oportunidades de investimentos e projetos. Por outro lado os acionistas não tem a mesma riqueza de informações de natureza gerencial e precisam conhecer as firmas por meio dos prospectos e demonstrações financeiras que as mesmas divulgam antes do IPO.

É a partir dessas demonstrações que eles irão formar os preços que estarão dispostos a pagar pelas ações das firmas. Cientes disso os gestores das firmas que abrem o seu capital poderão usar de seu poder discricionário para influenciar previamente os números que constarão dessas demonstrações financeiras visando obter a melhor valorização para os papéis nos IPOs, configurando assim um conflito de agência entre os proprietários/gestores atuais da firma e os acionistas potenciais.

Todavia, essas práticas de gerenciamento de resultados poderão ser impulsionadas por alguns fatores, tais como legislação e normatização menos rigorosa, assim como por outros determinantes como aqueles ligados ao ambiente econômico e o estágio de desenvolvimento do mercado de capitais do país. Assim sendo, dada a possibilidade de ocorrência de gerenciamento de resultados em processos de abertura de capital de firmas no mercado brasileiro, a presente pesquisa buscou elucidar a seguinte questão: Quais os principais determinantes da prática de Gerenciamento de Resultados (GR) financeiros por parte de empresas brasileiras que realizaram Ofertas Públicas Iniciais de Ações (IPOs) no mercado de capitais brasileiro?

Estabelece-se que há incentivos para gerenciar resultados por parte dos gestores das empresas que realizam IPOs e a existência de condicionantes que possam impactar em uma maior ocorrência desta prática. Neste sentido, para nortear a pesquisa, foi elaborada a seguinte Hipótese de Pesquisa: Existem determinantes internos e externos à empresa que favorecem ou inibem a prática do gerenciamento de resultados no contexto dos IPOs, tais como a presença de private equity/venture capital (PE/VC), a aderência às IFRS (Normas Internacionais de Contabilidade), a Governança Corporativa, a sustentabilidade empresarial, a condição geral da economia, a realização de uma oferta subsequente de ações (SEO) e a reputação do auditor caracterizado como importante gatekeeper no contexto do gerenciamento de resultados.

Todas estas variáveis são apontadas na literatura como sendo importantes para explicar os níveis de accruals discricionários apresentados pelas empresas, ou seja, os condicionantes para a prática do gerenciamento de resultados contábeis. Além disso, conforme apontam estudos como os de Roosenboom et al. (2003), Elston e Yang (2006), Lin e Tian (2012), Khurshed et al. (2014), Carvalho et al. (2020), outras variáveis de controle que funcionam como proxy para o tamanho, oportunidades de crescimento, desempenho, alavancagem e tangibilidade, além do nível de capital de giro também foram incorporadas na pesquisa para analisar os níveis de accruals das firmas

Nos tópicos a seguir encontram-se o Referencial Teórico da pesquisa onde se discute aspectos do processo de oferta pública de ações; conceitos e literatura ligados à prática de gerenciamento de resultados contábeis, bem como bibliografia que trata dessa prática em um contexto de abertura de capital. A seguir é apresentada a Metodologia da pesquisa com a descrição dos procedimentos e modelos utilizados para identificar o gerenciamento de resultados em IPOs, bem como para testar quais são os determinantes dessa prática. Por fim, são analisados os Resultados da pesquisa e apresentadas as Considerações Finais e Bibliografia consultada. 


\section{REFERENCIAL TEÓRICO}

\subsection{Oferta Pública Inicial de Ações (Initial Public Offering - IPO)}

O capital inicial necessário para se abrir um negócio normalmente é fornecido pelo próprio empreendedor e familiares. Contudo, estes não conseguem financiar um negócio em crescimento, o que leva grande parte das vezes, à necessidade de capital externo por parte das empresas no mercado (Berk \& Demarzo, 2009).

Um resultado significativo dos trabalhos empíricos sobre IPOs é que o fator crucial na decisão das empresas de ter suas ações publicamente negociadas em bolsa são as condições do mercado de capitais. Embora também seja afetada por alguns fatores internos às empresas, essa escolha não reflete inevitavelmente o estágio de desenvolvimento da empresa. No mercado, há tanto empresas de grande porte com capital fechado como pequenas empresas listadas em bolsa. Inclusive é realidade o incentivo ao acesso gradual a bolsa de pequenos projetos com boas perspectivas de crescimento (Aldrighi et al, 2010).

Entre os fatores usualmente identificados como responsáveis pelo "boom" no mercado de IPOs entre 2002 e 2007 destacam-se os sólidos fundamentos macroeconômicos da economia brasileira; os avanços nas reformas microeconômicas, especialmente a reforma da lei das S.A. em 2007 e da lei disciplinando as atribuições e responsabilidades da CVM em 2002; a farta liquidez internacional; e a criação em 2000 dos níveis diferenciados de exigências de governança corporativa pela B3, aos quais as empresas podem aderir voluntariamente por meio de contrato privado. De fato, a demanda dos investidores, sobretudo estrangeiros, por padrões mais exigentes de governança corporativa e transparência teve papel decisivo na concentração das listagens dos IPOs no Novo Mercado no período entre 2004 e 2008 (Aldrighi et al, 2010).

Contudo, cabe destacar que existem algumas características marcantes do processo de abertura de capital que oferecem oportunidades e incentivos para gerenciar os lucros. Há relativamente pouca informação disponível para os investidores a partir de fontes públicas sobre as empresas privadas fazendo com que os investidores confiem principalmente nas declarações financeiras relatadas no prospecto. Teoh, Wong e Rao (1998) relatam que quase não há cobertura da mídia nas empresas nos anos anteriores a oferta.

\subsection{Gerenciamento de Resultados Contábeis}

Baseada na ótica da teoria da firma, a contabilidade surge para contribuir com os mecanismos de governança, reduzindo o impacto dos conflitos de agência, através da redução da assimetria informacional, além da possibilidade de ser visualizada como instrumento de poder e de controle organizacional. Seguindo a linha de redução de assimetria informacional, as pesquisas buscam analisar a confiabilidade da mensuração contábil, pois suas métricas possuem aspectos subjetivos, como por exemplo, os accruals. O regime de competência (accrual basis) e outros conceitos mudam conforme a estrutura institucional na qual a empresa está inserida, como sistema de governança, auditoria, regulação contábil e sistema de normas, enforcement, relações jurídicas dos contratos, investidores, etc. (Paulo, 2006).

A primeira vista, os lucros são importantes porque as informações contábil-financeiras também o são. Neste âmbito, a informação contábil possui duplo papel:

1) Informatividade - Investidores demandam informações para prever fluxos de caixa futuros e avaliação de risco (Lucros contábeis estão mais associados com os preços das ações do que fluxos de caixa, vendas e demais dados das demonstrações contábil-financeiras).

2) Administração - Separação entre propriedade e gestão - Informações que servem para os proprietários monitorar as ações dos gestores que estão em posição privilegiada em relação aos proprietários (Teoria da Agência). Uma função dos relatórios financeiros é restringir a gestão para 
agir no interesse dos acionistas, ou pelo menos, direcionar para a congruência entre os objetivos dos mesmos (Watts \& Zimmerman, 1978).

Assim pode-se destacar que o gerenciamento das informações contábil-financeiras pode ser definida como a utilização das ações discricionárias por parte dos gestores para alterar a interpretação da realidade econômica e financeira da empresa (Paulo, 2006). Concomitantemente, é importante destacar que compreender quais seriam os condicionantes para a prática gerenciamento de resultados no contexto dos IPOs é de extrema relevância dado que os IPOs se caracterizam como um importante evento econômico e se relacionam de forma estreita com o gerenciamento de resultados que pode colocar em risco a capacidade informacional da contabilidade, principal meio de comunicação entre empresa e mercado, prejudicando assim a alocação de recursos entre empresas e entre países.

A informação contábil objetiva apresentar, de forma fidedigna e imparcial, o verdadeiro desempenho econômico e financeiro da empresa. Considerando que os relatórios contábil-financeiros transmitem informações da empresa e de sua gestão aos stakeholders, as normas contábeis precisam permitir que os gestores usem de sua expertise para exercer julgamento sobre as demonstrações contábil-financeiras em prol do reporte da realidade empresarial de forma mais adequada (Healy \& Wahlen, 1999).

Entretanto, o gerenciamento de resultados pode ser considerado uma estratégia de geração de lucro contábil que é realizada através da discrição administrativa sobre escolhas contábeis e fluxos de caixa. Desta forma, se caracteriza como um conjunto de atos que afetam o lucro contábil reportado ou sua interpretação, a partir das decisões de produção e investimentos, que, em parte determinam os lucros econômicos subsequentes, passando pela escolha do tratamento contábil, finalizando com ações que afetam a interpretação dos resultados (Ronen \& Yaari, 2008).

Os estudos vinculados ao gerenciamento de resultados relacionados à flexibilidade na adoção das normas e práticas contábeis (EAM - Accruals Earnings Management - com consequências artificiais), como este trabalho, decompõem os accruals da seguinte forma:

i) accruals não discricionários (nondiscretionary accruals - NDA); e

ii) accruals discricionários (discretionary accruals - DA).

Os accruals não discricionários (NDA) serão aqueles que surgem das transações realizadas em um período e que são normais para uma entidade, dadas a sua performance, estrutura de financiamento, estratégia de negócios, convenções do seu setor e demais fatores políticos, sociais e econômicos. São inerentes às atividades da empresa. Já os accruals discricionários (DA) serão aqueles que surgem a partir de escolhas e tratamentos contábeis adotados com a finalidade de gerenciar resultados. São artificiais e teriam como objetivo somente manipular o resultado contábil.

As reversões serão accruals originados de transações e eventos originados de períodos anteriores que precisam ser revertidos no período atual (Ronen \& Yaari, 2008). Compreender as reversões é de extrema relevância, pois estas são responsáveis por "denunciar" as práticas oportunistas adotadas pelos gestores em períodos anteriores.

Inúmeras pesquisas nacionais e internacionais envolvendo gerenciamento de resultados tais como as de Jones (1991), Dechow, Sloan e Sweeney (1995), Teoh, Welch e Wong (1998), Martinez (2001), Kothari, Leone e Wasley (2005), Paulo (2006), Alhadab, Clacher e Keasey (2013), Gioielli, Carvalho e Sampaio (2013), consideram os accruals discricionários como proxy do GR. Daí a importância de se utilizar tais técnicas na análise deste tema.

\subsection{Pesquisas empíricas sobre gerenciamento de resultados em ofertas públicas iniciais}

Paulo (2006) verificou a relação entre a oferta pública de ações e o nível de discricionariedade dos resultados contábeis. O estudo foi realizado nas companhias abertas brasileiras que efetuaram ofertas de ações no período de 2000 a 2003, através da utilização dos modelos para detecção de gerenciamento de resultados e de testes de hipóteses, com o intuito de analisar a existência de 
comportamentos diferentes de accruals discricionários ao longo do período observado. A literatura apresenta evidências de que os administradores têm incentivos para alavancar seus resultados antes do lançamento de títulos no mercado de capitais, bem como estimular a elevação dos preços das ações para incrementar o aporte de recursos financeiros dos seus novos investidores. Utilizou a abordagem empírica através da aplicação de modelos econométricos descritos na literatura que medem os accruals discricionários (proxy para o gerenciamento de resultados) como o Modelo de Jones (1991) e o Modelo de Jones Modificado (1995).

Aldrighi et al. (2010) examinaram os fatores determinantes na decisão das empresas de realizaram ofertas públicas iniciais (IPOs) na B3 no período entre 2002 e 2007. Investigaram a possível influência sobre essa decisão de diversas características econômico financeiras ex ante das empresas, tais como: tamanho, gastos de investimento, crescimento das vendas, lucratividade, grau de endividamento, setor em que atuam e oportunidades de crescimento no setor. Analisaram ainda as escolhas dos empresários relacionadas ao formato dessas IPOs, como: i) segmento de listagem; ii) fração do maior acionista no capital votante da empresa após a IPO; e iii) a parcela de free-float. Por fim, verificou-se se há diferenças no desempenho e nas escolhas financeiras e de investimento antes e após o IPO.

Neste cenário, Baptista (2008) delineou o perfil das empresas brasileiras com maior propensão ao gerenciamento de resultados contábeis. Foi investigado se existe um padrão de accruals discricionários entre categorias de variáveis qualitativas e quantitativas que representam os incentivos das empresas a praticar o gerenciamento de resultados. As variáveis analisadas incluíram indicadores econômicos, de mercado, medidas de concentração acionária e tamanho, além de características relacionadas à governança, relacionamento com a auditoria, remuneração de executivos, captação de recursos em bolsa de valores estrangeira e sanção do órgão regulador responsável. Percebeu-se que maiores níveis de accruals podem estar associados a empresas com maiores expectativas de crescimento, maior exposição ao risco e menor concentração acionária.

Quanto às variáveis rentabilidade patrimonial e operacional, endividamento e rentabilidade do acionista, maiores valores de accruals foram associados tanto a menores como a maiores níveis destas variáveis. Verificou-se que são mais propensas a praticar gerenciamento de resultados contábeis as empresas não listadas nos segmentos especiais da B3, que não apresentam programas de ADR e que têm planos de remuneração variável como opções de ações, entre outros.

Gioielli, Carvalho e Sampaio (2013) investigaram o gerenciamento de resultados em IPOs e o papel de gestores de capital de risco (private equity/venture capital - PE/VC) em dificultar tal prática, pois, investidores de capital de risco têm incentivos para forçar suas empresas investidas a manter boas práticas de governança corporativa, mesmo depois do IPO. Para estimar as acumulações discricionárias, os autores usaram três diferentes modelos econométricos: o Modelo de Jones (Jones, 1991), o Modelo de Jones Modificado (Dechow, Sloan \& Sweeney, 1995), e o Modelo de Jones Modificado com ROA (Retorno sobre Ativos) (Kothari, Leone \& Wasley, 2005) com dados no formato cross-sectional. Ao analisar o GR, os autores percebem que as empresas investidas por $\mathrm{PE} / \mathrm{VC}$ e as empresas não investidas por PE/VC deveriam ser tratadas como amostras diferentes. Para os IPOs de empresas com investimento de PE/VC, o GR foi marginal, geralmente relacionado às características das empresas e pouco relacionado às fases do IPO. De forma diferente, para os IPOs de empresas não investidas por PE/VC o GR foi significativo, geralmente relacionado às fases do IPO e pouco relacionado às características das empresas.

\section{METODOLOGIA}

Os dados coletados se referem às demonstrações contábil-financeiras das empresas que realizaram IPO recentemente no Brasil, sendo coletados dados destas empresas entre os anos de 2001 e 2013. Em contexto nacional, observou-se um processo crescente de oferta pública de ações de empresas brasileiras iniciado em 2002, quando apenas uma empresa ofertou publicamente suas ações. 
Em 2004, sete empresas realizaram suas primeiras ofertas públicas. Em 2006, esse número chegou a 26. Em 2007, 64 empresas realizaram IPO. Em 2008, quatro e em 2009, apenas seis. Em 2010 foram mais onze, igualmente a 2011. Em 2013 mais treze empresas realizaram IPO e lançaram ações na B3.

No período analisado, 155 empresas passaram a negociar suas ações na bolsa. Juntas, essas empresas captaram montante superior a R $\$ 100$ bilhões (BM\&FBovespa, 2014). O período escolhido justifica-se pelo fato de que a partir dos anos de 2000 e 2002 muitos eventos de suma importância passaram a contribuir para o desenvolvimento do mercado de capitais brasileiro como a criação do Novo Mercado em 2000 e ainda, a reforma da lei que disciplina as atribuições e responsabilidades da CVM, órgão responsável por regulamentar o mercado de títulos no Brasil, em 2002.

Os dados contábeis utilizados foram aqueles divulgados trimestralmente, disponíveis no sistema Economática ${ }^{\circledR}$, que serão tabulados com o auxílio do software Microsoft Excel®. Para análise estatística foi utilizado o software STATA®. Consideraram-se aqueles IPOs de empresas que disponibilizaram suas demonstrações financeiras de forma consecutiva em anos anteriores e posteriores ao lançamento. Empresas com dados insuficientes, ou seja, quando o nível de divulgação não permitir o cálculo dos accruals serão excluídas da amostra.

A coleta dos dados compreendeu os demonstrativos contábil-financeiros das empresas listadas na B3 e seus prospectos de IPOs, sendo obtidos dados nos sites da Comissão de Valores Mobiliários $(\mathrm{CVM})$, da B3 e sites institucionais, além da utilização do banco de dados Economática®.

Foram excluídas as ofertas realizadas por instituições financeiras e do setor investimento mobiliário, pois estas têm características, transações e controles diferenciados das empresas dos demais segmentos. As empresas desses setores geralmente são excluídas de algumas pesquisas uma vez que apresentam demonstrações financeiras com padrões e características específicas em seus planos de contas que as diferenciam das empresas dos demais setores de atividade. Particularmente no caso de instituições financeiras, o COSIF será o Plano de Contas que deve ser obrigatoriamente utilizado pelas instituições do sistema financeiro brasileiro autorizadas a funcionar pelo Banco Central do Brasil de conformidade com o disposto no item XII do artigo $4^{\circ}$ da Lei 4.595/1964.

Assim sendo, como critério para essa exclusão, foi utilizada a classificação setorial da B3, eliminando-se todas as empresas do setor econômico "Financeiro e Outros". Este setor é composto pelos seguintes segmentos de atuação: Bancos, Sociedades de Crédito e Financiamento, Sociedades de Arrendamento Mercantil, Securitizadoras de Recebíveis, Seguradoras, Exploração de Imóveis, Holdings Diversificadas, Fundos e Outros.

\subsection{Identificação dos Accruals Discricionários}

Os accruals totais foram estimados pelo denominado "enfoque do balanço" (equação 1). Esta abordagem de estimação dos accruals baseada nas contas do Balanço Patrimonial é a mais utilizada na literatura, e também utilizada neste trabalho (Jones (1991); Dechow, Sloan \& Sweeney (1995); Teoh, Welch \& Wong (1998); Healy \& Wahlen (1999); Martinez (2001); Bispo (2010), Alhadab, Clacher \& Keasey (2013), Gioielli, Carvalho \& Sampaio (2013)). A opção pelo método da mudança em sucessivas contas patrimoniais (Equação 1), que foi sugerido por Jones (1991) e segue sendo referência para os modelos que objetivam detectar o gerenciamento de resultados, também se deve ao fato de que, no Brasil, a demonstração dos fluxos de caixa não era obrigatória até a promulgação da lei 11.638/07, tornando-se necessário calcular os accruals totais pelas diferenças no Balanço Patrimonial.

O nível de accruals totais de uma firma é dado pela diferença entre a variação no ativo circulante e nas disponibilidades diminuído da diferença entre a variação do passivo circulante e nos empréstimos e financiamentos de curto prazo diminuído da depreciação e amortização reconhecidas no período.

$$
A C T_{i t}=\left(\left(\triangle A C_{i t}-\triangle D I S P_{i t}\right)-\left(\triangle P C_{i t}-\triangle F C P_{i t}\right)-\left(D E P_{i t}+A M O R T_{i t}\right)\right)
$$


Ainda quanto aos accruals é importante destacar que o desafio de qualquer modelo no contexto do gerenciamento de resultados é sinalizar a melhor proxy que evidencia tal prática. Para o cálculo dos accruals discricionários (proxy para o gerenciamento de resultados) deve se levar em consideração que os accruals totais se dividem em accruals não discricionários (normais para a empresa) e accruals discricionários (artificiais e ligados aos incentivos para gerenciar resultados).

Objetivando a realização de inferências mais robustas, o modelo desenvolvido por Kothari, Leone e Wasley (2005) (Modelo de Performance-Matching (2005)) que incorpora a performance no cálculo dos accruals foi utilizado neste trabalho paralelamente ao Modelo de Jones Modificado (2005) desenvolvido por Dechow, Sloan e Sweeney (1995), uma vez que, a capacidade explicativa do modelo de regressão pode ser melhorada com a inclusão da variável performance das empresas. As equações do Modelo de Jones Modificado e de Performance-Matching utilizados na pesquisa são dados pelas equações (2) a (4) a seguir:

$$
\frac{A C T_{i t}}{A T_{i t-1}}=\hat{\alpha}_{i}\left(\frac{1}{A T_{i t-1}}\right)+\hat{\beta}_{1 i}\left(\frac{\triangle R E C_{i t}-\triangle C R_{i t}}{A T_{i t-1}}\right)+\hat{\beta}_{2 i}\left(\frac{A P_{i t}}{A T_{i t-1}}\right)+\varepsilon_{i t}
$$

Sendo que:

$$
\frac{A N D_{i t}}{A T_{i t-1}}=\alpha_{i}\left(\frac{1}{A T_{i t-1}}\right)+\beta_{1 i}\left(\frac{\triangle R E C_{i t}-\triangle C R_{i t}}{A T_{i t-1}}\right)+\beta_{2 i}\left(\frac{A P_{i t}}{A T_{i t-1}}\right)
$$

Em que:

$\boldsymbol{A C T _ { i t }}=$ accruals totais da empresa $i$ no período $t$;

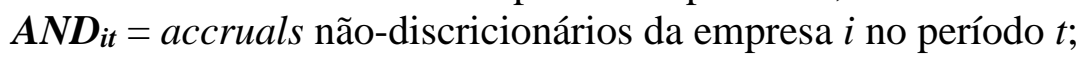

$\boldsymbol{A} \boldsymbol{T}_{i-1}=$ ativo total da empresa $i$ no período $t-1$;

$\triangle \boldsymbol{C} \boldsymbol{R}_{i t}=$ contas a receber da empresa $i$ no período $t$ menos o valor das contas a receber do período $t-1$;

$\Delta \boldsymbol{R} \boldsymbol{E} \boldsymbol{C}_{i t}=$ receitas operacionais líquidas da empresa $i$ no período $t$ menos as receitas do período $t-1$;

$\boldsymbol{A P}_{i t}=$ ativo permanente da empresa $i$ no período $t$;

$\mathcal{E}_{i t}=$ termo de erro da regressão padronizado por $\mathrm{AT}_{i t-1 .}$.

O modelo proposto por Dechow, Sloan e Sweeney (1995), apesar de ser uma versão modificada do modelo de Jones (1991), leva em consideração o fato de que o procedimento para cálculo dos accruals discricionários é o mesmo. Logo, serão utilizados os coeficientes estimados $\left(\hat{\alpha}_{i}, \hat{\beta}_{1 i}\right.$ e $\left.\hat{\beta}_{2 i}\right)$ para o cálculo dos accruals não-discricionários e, em seguida, o resultado da diferença entre os accruals totais (ACT) e os accruals não-discricionários (AND) resultará na estimativa do valor dos accruals discricionários (AD).

Já pela abordagem de Kothari, Leone e Wasley (2005) que leva em conta o desempenho recente da firma (ROA do período anterior) como um dos determinantes do nível normal de accruals, teria-se que estimar:

$$
\frac{A N D_{i t}}{A T_{i t-1}}=\alpha_{0 i}+\beta_{1 i}\left(\frac{1}{A T_{i t-1}}\right)+\beta_{2 i}\left(\frac{\triangle R E C_{i t}-\triangle C R_{i t}}{A T_{i t-1}}\right)+\beta_{3 i}\left(\frac{A P_{i t}}{A T_{i t-1}}\right)+\beta_{4 i}\left(R O A_{i t-1}\right)
$$

Em que:

$\boldsymbol{A N D}_{i t}=$ accruals não discricionários padronizados pelo ativo total de $t-1$;

$\triangle \boldsymbol{C R}_{i t}=$ contas a receber da empresa $i$ no período $t$ menos o valor das contas a receber do período $t-1$; $\Delta \boldsymbol{R E} \boldsymbol{C}_{i t}=$ receitas operacionais líquidas da empresa $i$ no período $t$ menos as receitas do período $t-1$; $\boldsymbol{A P}_{i t}=$ ativo permanente da empresa $i$ no período $t$;

$\boldsymbol{R O} \boldsymbol{A}_{i t-1}=$ retorno sobre o ativo do período $t-1$; 
$A T_{i t-1}=$ ativo total da empresa $i$ do período $t-1$.

A parte dos accruals totais (variável dependente) não explicada pelos accruals não discricionários (regulares/normais para a empresa), será estimada pelo termo de erro $\left(\varepsilon_{i t}\right)$. Ou seja, esse termo representará a estimativa do valor dos accruals discricionários (proxy para o gerenciamento de resultados).

\subsection{Modelo Para Análise dos Determinantes do Gerenciamento de Resultados Contábeis no Contexto das IPOs}

A modelagem de dados em painel relaciona indivíduos, empresas, países, etc., em relação ao tempo, havendo a heterogeneidade entre as unidades. Possibilita combinar séries temporais com observações de corte transversal, oferecendo maiores informações, maior variabilidade, reduzindo a colinearidade entre as variáveis, além de maior eficiência estatística ao melhor medir os efeitos que não podem ser observados em corte transversal ou em séries temporais de forma isolada (Gujarati \& Porter, 2011; Baltagi \& Boozer, 2009).

Para testar a hipótese desta pesquisa, será utilizada regressão com dados em painel em que a variável dependente é o nível de gerenciamento de resultados para a empresa $i$ no período $t$, GRit (medido pelos accruals discricionários para a empresa $i$ no período $t$ ). As variáveis apontadas por autores (Cupertino, Martinez \& Costa Jr. 2014; Dechow, Sloan \& Sweeney, 1995; Ye, 2006; Baptista, 2008; Kothari, Leone \& Wasley, 2005; Teoh, Welch \& Wong, 1998; Hochberg, 2011; Martinez, 2001; Morsfield \& Tan, 2006; Ronen \& Yaari, 2008; Gioielli, Carvalho \& Sampaio, 2013; Fasolin \& Klann, 2014) como condicionantes para o nível de accruals das empresas são incorporadas na regressão.

Dessa forma, o modelo utilizado nesta pesquisa (tomando como base autores como Gioielli, Carvalho e Sampaio (2013), Baptista (2008) e Hochberg (2011)) que inclui diversas variáveis que influenciam os incentivos para a prática do gerenciamento de resultados é:

$$
\begin{aligned}
G_{i t}= & \beta_{0}+\beta_{1} \text { FaseIPO }_{i t}+\beta_{2} \text { PEVC }_{i t}+\beta_{3} \text { IFRS }_{i t}+\beta_{4} \text { GC }_{i t}+\beta_{5} \text { ISE }_{i t}+\beta_{6} \triangle \text { PIB }_{i t}+\beta_{7} \text { SEO }_{i t}+\beta_{8} \text { Auditor }_{i t} \\
& +\beta_{9} \text { Quente }_{i t}+\beta_{10} \text { Tamanho }_{i t}+\beta_{11} \text { Crescimento }_{i t}+\beta_{12} \text { Alavancagem }_{i t}+\beta_{13} \text { Desempenho }_{i t}+ \\
& \beta_{14} \text { Tangibilidade }_{i t}+\beta_{15} \text { CapitaldeGiro }_{i t}+c_{i}+\varepsilon_{i t}
\end{aligned}
$$

Em que:

$\boldsymbol{G R}_{i t}$ : é o nível de gerenciamento de resultados para a empresa $i$ no período $t$, medido pelos accruals discricionários para a empresa $i$ no período $t$ (calculados pelo Modelo de Jones Modificado e pelo Modelo de Performance-Matching).

Fase IPO ${ }_{i t}$ : variável dummy que assume o valor um para as 11 observações (trimestres) do período chave, o período que antecede, marca e imediatamente posterior ao IPO (ano-1, ano $\left.\mathrm{e} \mathrm{ano}_{+1}\right)$ para a empresa $i$, e zero, caso contrário.

Gioielli, Carvalho e Sampaio (2013) enfatizam que no período chave para o IPO (período que antecede imediatamente a oferta) o incentivo dos gestores para manipular os resultados é mais forte. Teoh, Welch e Wong (1998) elucidam que assim como nos períodos imediatamente anteriores (início de formação dos accruals), o período que marca (inflacionar o preço das ações) e imediatamente posterior (evitar processos judiciais; período de lockup -restrição de venda dos papéis dos administradores), também são caracterizados pelos altos incentivos dos gestores para gerenciar resultados. Portanto, espera-se que o coeficiente desta variável responsável por captar as observações da empresa $i$ no período crítico para o IPO seja positivo, indicando que nos trimestres referentes aos anos $(-1,0$ e +1$)$ os níveis de accruals discricionários são maiores do que em períodos posteriores $(\operatorname{anos}+2 \mathrm{e}+3)$.

Presença de private equity/venture capital $\left(\boldsymbol{P E} / V C_{i t}\right)$ : variável dummy que assume o valor um quando a observação vem de uma empresa com investimentos de PE/VC e zero, caso contrário. 
Ronen e Yaari (2008) assim como Gioielli, Carvalho e Sampaio (2013) enfatizam que a presença de um gestor de capital de risco (PE/VC) com altos investimentos, alta reputação e poder para manter contato e participar das reuniões do conselho administrativo da empresa investida inibe a prática do gerenciamento de resultados por parte dos administradores dessas empresas. Por outro lado, estes gestores de capital de risco podem corroborar com a administração da empresa na adoção de escolhas oportunistas dado que ambos podem objetivar uma reação positiva do mercado. Portanto, o sinal esperado para o coeficiente desta variável não é claro, podendo as empresas com investimentos de PE/VC apresentar, tanto menores quanto maiores níveis de accruals discricionários.

Aderência às IFRS (IFRS $i t)$ : variável dummy que assume o valor um quando a observação for referente aos anos posteriores a 2009 (obrigatória no Brasil a partir do exercício findo em 2010), e zero, nos demais casos.

Segundo Cupertino, Martinez e Costa Jr. (2014), o gerenciamento por accruals diminuiu com a implantação do IFRS, provavelmente pelo aumento da qualidade dos números reportados decorrente do processo de harmonização das demonstrações financeiras às regras internacionais de contabilidade. Jeanjean e Stolowy (2008) encontraram, em países code-law como a França, um aumento no nível de GR. Portanto, o sinal esperado para o coeficiente desta variável não é claro, podendo a aderência às normas internacionais estar associada tanto a menores quanto a maiores níveis de accruals discricionários.

Governança Corporativa $(\boldsymbol{G C}$ it $)$ : variável dummy que assume o valor um quando a observação vem de uma empresa pertencente ao Novo Mercado, e zero, caso contrário.

Ronen e Yaari (2008) assim como Martinez (2001) elucidam que a adoção de mecanismos de Governança Corporativa se caracteriza como fatores limitadores para a prática do gerenciamento de resultados. Assim sendo, é esperado que o coeficiente encontrado para esta variável seja negativo indicando que quando da presença de mecanismos de governança corporativa, há menor nível de acumulações discricionárias assumidas pelas empresas.

Sustentabilidade Empresarial (ISE $\boldsymbol{E}_{i t}$ ): variável dummy que assume o valor um quando a observação vem de uma empresa presente no ISE (Índice de Sustentabilidade Empresarial), e zero, caso contrário.

Assim como para a Governança Corporativa, Ronen e Yaari (2008) elucidam que a Sustentabilidade Empresarial também se caracteriza como fator limitador para a prática do gerenciamento de resultados contábeis. Empresas sustentáveis estão comprometidas e diferenciamse em termos de qualidade, compromisso com o desenvolvimento sustentável, equidade, transparência e prestação de contas (BM\&FBOVESPA, 2014). Assim sendo, é esperado que o coeficiente encontrado para esta variável seja negativo indicando que empresas sustentáveis apresentam menor nível de acumulações discricionárias.

Condição Geral da Economia $\left(\triangle P I B_{i t}\right)$ : representada pela variação no Produto Interno Bruto (PIB) entre os trimestres $t$ - 1 e $t$, incorporada para capturar a atividade econômica.

Para Cupertino, Martinez e Costa Jr. (2014) a condição geral da economia influencia o nível de accruals discricionários assumidos pelas empresas, pois, dependendo da situação econômica, as empresas poderão aumentar ou reduzir ainda mais seus accruals no intuito de gerenciar seus resultados. O sinal esperado para o coeficiente desta variável não é claro, podendo estar relacionada à condição geral da economia tanto ao aumento quanto à redução das acumulações discricionárias (Ronen e Yaari, 2008).

Realização de uma SEO (SEO $\boldsymbol{O}_{i t}$ ): variável dummy que assume o valor um se a empresa $i$ realizou uma oferta subsequente de ações e se o trimestre $t$ está compreendido no intervalo com incentivos para o gerenciamento da nova oferta $\left(\operatorname{anos}_{+1,+2}\right.$ e +3$)$, e zero, caso contrário.

Rangan (1998), Teoh, Wong e Rao (1998), Bispo (2010) e Gioielli, Carvalho e Sampaio (2013) elucidam que, da mesma forma que em um IPO, as empresas têm grandes incentivos para gerenciar seus resultados quando realizam uma oferta subsequente de ações (SEO). Assim, espera-se encontrar sinal positivo para esta variável corroborando com os autores mencionados, ou seja, as 
empresas que realizaram IPO, e posteriormente, SEO, no período estudado, apresentaram maior nível de acumulações discricionárias em períodos posteriores ao IPO e próximos a SEO.

Reputação do Auditor (Auditorit): variável dummy que assume o valor um quando a observação vem de uma empresa com demonstrações contábeis-financeiras auditadas por uma das empresas de auditoria líderes de mercado, do chamado grupo "Big Four" (KPMG, PricewaterhouseCoopers, Deloitte Touche Tohmatsu e Ernst \& Young), e zero, caso contrário.

Para Morsfield e Tan (2006), Baptista (2008), Ronen e Yaari (2008) e Gioielli, Carvalho e

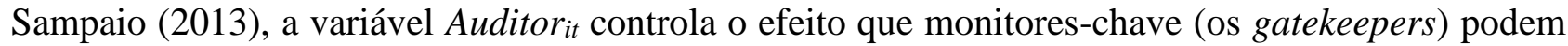
ter em mitigar o gerenciamento de resultados. Martinez (2001) também ressalta que quanto mais independente e eficiente for a firma de auditoria menor será a propensão para que esta tolere o gerenciamento de resultados. Por este motivo, espera-se um sinal negativo para esta variável.

Momentos Quentes (Quente $i t$ ): variável dummy que assume o valor um quando a observação vem de um trimestre caracterizado como "quente", e zero, caso contrário. Os trimestres são denominados "quentes e frios" em função do volume de IPOs realizados nos trimestres analisados. Assim são considerados "quentes" os trimestres com número de ofertas superior à média apresentada no período, e "frios" os trimestres com número de ofertas inferior a média.

A razão por trás da definição implica que, se houver uma percepção por parte dos gestores de que há uma janela de oportunidade onde o custo de capital via ações está baixo relativo a outras modalidades de financiamento, haverá uma concentração natural de IPOs nesse período e uma tendência dos gestores em ofertar volume maior de ações para aproveitar o momento percebido como favorável. (ALTI, 2006). Neste contexto, estes momentos quentes, podem também ser favoráveis para a prática do gerenciamento de resultados contábeis por parte dos gestores dado que usufruindo destas janelas de oportunidade os gestores podem abastecer o mercado com expectativas falsas, fruto do gerenciamento de resultados contábeis. Assim, espera-se encontrar sinal positivo para esta variável corroborando com as expectativas relacionadas às janelas de oportunidade, momentos caracterizados como quentes, de economia aquecida.

Tamanho $_{i t}$ : representada pelo logaritmo natural dos ativos totais da empresa $i$ no trimestre $t$ (em milhões de reais).

Ronen e Yaari (2008) assim como Hochberg (2011) e Martinez (2001) enfatizam que empresas maiores possuem demonstrações contábeis-financeiras mais complexas (com maiores ruídos), e, portanto, podem usufruir deste aspecto para manipular seus resultados. Por outro lado, grandes empresas estão mais sujeitas a serem monitoradas pelos gatekeepers (monitores como os analistas de mercado) e isso reduz as oportunidades para o gerenciamento. Desta forma, não há uma expectativa clara sobre o sinal associado à variável Tamanho $i$.

Crescimento ${ }_{i t}$ : representada pela variação na receita operacional líquida da empresa $i$ entre os trimestres $t-1$ e $t$, dividida pela receita líquida operacional no trimestre $t-1$.

Hochberg (2011), Baptista (2008) e Fasolin e Klann (2014) salientam que empresas com maiores taxas de crescimento estão mais propensas a gerenciar seus resultados e, consecutivamente, apresentar maiores níveis de accruals discricionários uma vez que estão em corrente expansão, utilizando de algum grau de imprecisão dos números relatados. Assim, sinal positivo é esperado.

Alavancagem $_{i t}$ : representada pela alavancagem da empresa $i$ no trimestre $t$, calculada como um menos a razão entre o patrimônio líquido e os ativos totais.

Morsfield e Tan (2006) assim como Ronen e Yaari (2008) e Martinez (2001) elucidam que empresas altamente alavancadas têm grandes incentivos para gerenciar seus resultados para cima (inflar seus resultados) objetivando evitar a violação de cláusulas contratuais para com terceiros. Entretanto, enfrentam um maior monitoramento por parte dos detentores desses títulos. Destarte, corroborando com Baptista (2008), não há uma expectativa clara para o sinal dessa variável.

Desempenho $_{\text {it: }}$ representada pelo retorno sobre os ativos (ROA) da empresa $i$ entre os trimestres $t-1$ e $t$, calculado como a razão entre o lucro líquido e os ativos totais. 
Baptista (2008) ressalta que o nível de accruals de uma empresa pode estar relacionado tanto a maiores quanto a menores valores para o ROA (proxy de desempenho). Desta forma, não há expectativa clara para o sinal do coeficiente dessa variável.

Tangibilidade $_{i t}$ : representada pelos investimentos em ativos fixos da empresa $i$ no trimestre $t$, calculada como a razão entre o ativo permanente e a receita operacional líquida de vendas.

Cupertino, Martinez e Costa Jr. (2014) enfatizam que para que as empresas sejam capazes de produzir em excesso e adotar medidas discricionárias, é necessário ter ativos fixos (operacionais) em nível suficiente para suportar esse aumento na produção e nas vendas. Espera-se que o coeficiente dessa variável seja positivo, indicando que empresas com maior nível de imobilização apresentem maior nível de accruals discricionários.

Capital de Giro it: representada pelo capital de giro da empresa $i$ no trimestre $t$, diminuída das disponibilidades e das dívidas (empréstimos e financiamentos) de curto prazo.

Ye (2006) elucida que o Capital de Giro se caracteriza como o recurso utilizado para sustentar as operações do dia-a-dia da empresa, ou seja, é o capital disponível para condução normal dos negócios da empresa, ele poderá apontar, dentro do ciclo operacional da empresa, comportamento anormal dos accruals correntes, uma vez que, o volume de capital de giro utilizado por uma empresa depende de seu volume de vendas, política de crédito e do nível de estoque mantido. Contudo, não há uma expectativa clara sobre o sinal do coeficiente dessa variável que pode estar relacionada tanto a maiores quanto a menores níveis de accruals.

Percebe-se que para a análise dos condicionantes do gerenciamento de resultados (explicação para o nível de accruals discricionários obtidos pelas empresas) incorpora-se no modelo diversas variáveis, dentre elas, variáveis financeiras de controle que são utilizadas nesta pesquisa como proxy para o: tamanho, expectativas de crescimento, nível de alavancagem, desempenho, tangibilidade e nível do capital de giro, além de outras variáveis que representam o período chave para o IPO, a presença de $\mathrm{PE} / \mathrm{VC}$, a aderência às normas internacionais de contabilidade (IFRS), a governança corporativa, a sustentabilidade empresarial, a atividade econômica geral, a realização de oferta experiente de capital (SEO) e a qualidade ou reputação das empresas de auditoria.

Não existe um consenso literário sobre quais variáveis possuem maiores efeitos para explicar o nível de accruals discricionários das empresas. Entretanto, as variáveis mencionadas são as mais comuns que vêm sendo utilizadas por autores nacionais e internacionais como condicionantes do gerenciamento de resultados.

Tabela 1: Variáveis do Modelo e seus Sinais Esperados de Acordo com Literatura

\begin{tabular}{|l|l|l|l|}
\hline \multicolumn{1}{|c|}{ Variáveis e (Siglas) } & \multicolumn{1}{|c|}{ Fórmula de Cálculo } & \multicolumn{1}{c|}{$\begin{array}{c}\text { Sinal } \\
\text { Esperado }\end{array}$} & \multicolumn{1}{c|}{ Autor(es) } \\
\hline $\begin{array}{l}\text { Gerenciamento de } \\
\text { Resultados (GR) }\end{array}$ & $\begin{array}{l}\text { (Nível de accruals discricionários } \\
\text { (AD) da empresa i no período t, } \\
\text { calculados pelo Modelo de Jones } \\
\text { Modificado e pelo Modelo de } \\
\text { Performance-Matching). }\end{array}$ & $\begin{array}{l}\text { Variável } \\
\text { Dependente }\end{array}$ & $\begin{array}{l}\text { Baptista (2008), Hochberg (2011) } \\
\text { e Gioielli, Carvalho e } \\
\text { Sampaio(2013). }\end{array}$ \\
\hline $\begin{array}{l}\text { A Fase do IPO } \\
\text { (FaseIPO) }\end{array}$ & Variável Dummy & Positivo & $\begin{array}{l}\text { Gioielli, Carvalho e Sampaio } \\
\text { (2013) e Teoh, Welch e Wong } \\
\text { (1998). }\end{array}$ \\
\hline $\begin{array}{l}\text { A presença de PE/VC } \\
\text { (PEVC) }\end{array}$ & Variável Dummy & $\begin{array}{l}\text { Ronen e Yaari (2008), Hochberg } \\
\text { (2011), Nakamura, Forte e Aguiar } \\
\text { (2006), Espenlaub e Garret (1999) } \\
\text { e Gioielli, Carvalho e Sampaio } \\
\text { (2013). }\end{array}$ \\
\hline $\begin{array}{l}\text { A aderência às IFRS } \\
\text { (IFRS) }\end{array}$ & Variável Dummy & $\begin{array}{l}\text { Jeanjean e Stolowy (2008), } \\
\text { Elbannan (2011) e Cupertino, } \\
\text { Martinez e Costa Jr. (2014) e } \\
\text { Silva et al (2014). }\end{array}$ \\
\hline $\begin{array}{l}\text { A Governança } \\
\text { Corporativa (GC) }\end{array}$ & Variável Dummy & $\begin{array}{l}\text { Baptista (2008), Martinez (2001) } \\
\text { e Ronen e Yaari (2008). }\end{array}$ \\
\hline
\end{tabular}




\begin{tabular}{|c|c|c|c|}
\hline $\begin{array}{l}\text { A Sustentabilidade } \\
\text { Empresarial (ISE) }\end{array}$ & Variável Dummy & Negativo & Ronen e Yaari (2008). \\
\hline $\begin{array}{l}\text { A Condição Geral da } \\
\text { Economia (PIB) }\end{array}$ & $\begin{array}{l}\text { Variação no Produto Interno Bruto } \\
\text { (PIB) trimestral entre os trimestres t } \\
-1 \mathrm{et} \text {. }\end{array}$ & Incerto & $\begin{array}{l}\text { Cupertino, Martinez e Costa Jr. } \\
\text { (2014) }\end{array}$ \\
\hline $\begin{array}{l}\text { A Realização de uma } \\
\text { SEO (SEO) }\end{array}$ & Variável Dummy & Positivo & $\begin{array}{l}\text { Rangan (1998), Teoh, Wong e } \\
\text { Rao (1998), Bispo (2010), } \\
\text { Hochberg(2011) e Gioielli, } \\
\text { Carvalho e Sampaio (2013). }\end{array}$ \\
\hline $\begin{array}{l}\text { A Reputação do Auditor } \\
\text { (Auditor) }\end{array}$ & Variável Dummy & Negativo & $\begin{array}{l}\text { Baptista (2008), Morsfield e Tan } \\
\text { (2006), Martinez (2001), Ronen e } \\
\text { Yaari (2008) e Gioielli, Carvalho } \\
\text { e Sampaio (2013). }\end{array}$ \\
\hline $\begin{array}{l}\text { Momentos Quentes } \\
\text { (Quente) }\end{array}$ & Variável Dummy & Positivo & $\begin{array}{l}\text { Alti (2006), Rossi Jr. e Marotta } \\
\text { (2010) e Melo e Lamounier } \\
\text { (2014). }\end{array}$ \\
\hline Tamanho & $\begin{array}{l}\text { Logaritmo natural dos ativos totais } \\
\text { da empresa i no trimestre } \mathrm{t} \text { ( } \mathrm{em} \\
\text { milhões de reais) }\end{array}$ & Incerto & $\begin{array}{l}\text { Hochberg (2011), Fasolin e Klann } \\
\text { (2014), Martinez (2001), Baptista } \\
\text { (2008), Gioielli, Carvalho e } \\
\text { Sampaio (2013), Zang (2012), } \\
\text { Cupertino, Martinez e Costa Jr. } \\
\text { (2014), Ronen e Yaari (2008) e } \\
\text { Castro (2008). }\end{array}$ \\
\hline Crescimento & $\begin{array}{l}\text { Variação na receita operacional } \\
\text { líquida da empresa i entre os } \\
\text { trimestres } \mathrm{t}-1 \text { e } \mathrm{t} \text {, dividida pela } \\
\text { receita líquida operacional no } \\
\text { trimestre } \mathrm{t}-1\end{array}$ & Positivo & $\begin{array}{l}\text { Baptista (2008), Hochberg } \\
\text { (2011), Cupertino, Martinez e } \\
\text { Costa Jr. (2014), Fasolin e Klann } \\
\text { (2014), Zang (2012) e Gioielli, } \\
\text { Carvalho e Sampaio (2013). }\end{array}$ \\
\hline Alavancagem & $\begin{array}{l}\text { Alavancagem calculada como um } \\
\text { menos a razão entre o patrimônio } \\
\text { líquido e os ativos totais. }\end{array}$ & Incerto & $\begin{array}{l}\text { Baptista (2008), (2006), Ronen e } \\
\text { Yaari (2008) Hochberg (2011), } \\
\text { Martinez (2001), Gioielli, } \\
\text { Carvalho e Sampaio (2013). }\end{array}$ \\
\hline Desempenho & $\begin{array}{l}\text { Retorno sobre os ativos (ROA) } \\
\text { calculado como a razão entre o } \\
\text { lucro líquido e os ativos totais. }\end{array}$ & Incerto & $\begin{array}{l}\text { Dechow, Sloan e Sweeney } \\
\text { (1995), McNichols (2000), } \\
\text { Baptista (2008), Cupertino, } \\
\text { Martinez e Costa Jr. (2014), } \\
\text { Kothari, Leone e Wasley (2005), } \\
\text { Zang (2012) e Gioielli, Carvalho } \\
\text { e Sampaio (2013). }\end{array}$ \\
\hline Tangibilidade & $\begin{array}{l}\text { Investimentos em ativos fixos } \\
\text { calculado como a razão entre o } \\
\text { ativo imobilizado e a receita } \\
\text { operacional líquida de vendas }\end{array}$ & Positivo & $\begin{array}{l}\text { Cupertino, Martinez e Costa Jr. } \\
\text { (2014). }\end{array}$ \\
\hline Capital de Giro & $\begin{array}{l}\text { Capital de Giro diminuído das } \\
\text { disponibilidades e das dívidas de } \\
\text { curto prazo. }\end{array}$ & Incerto & Ye (2006). \\
\hline
\end{tabular}

Fonte: Elaborado pelos autores.

\section{ANÁLISE DE RESULTADOS}

Para analisar quais seriam os condicionantes para o gerenciamento de resultados contábeis foi adotado modelo de dados em painel tendo como variável a ser explicada os níveis de accruals discricionários ponderados pelos ativos totais do período anterior para cada empresa nos anos $(-1,0$, +1 ) calculados com base nos Modelos de Jones Modificado (1995) e de Performance-Matching (2005).

Outro importante aspecto analisado está relacionado com as variáveis explicativas qualitativas (dummies). De acordo com a presença ou não do atributo da variável qualitativa foram comparados os níveis médios das acumulações discricionárias calculadas com base no Modelo de Jones 
Modificado e de Performance-Matching para a presença e ausência deste atributo entre as empresas e os períodos estudados.

Somente a variável GC apresentou resultados que não corroboram com a hipótese da pesquisa. Todas as outras variáveis apresentaram comportamento esperado, com destaque para as variáveis Fase IPO e Quente que sinalizaram para maiores níveis de accruals discricionários quando da presença do atributo demonstrando que nestes períodos são altos os incentivos para gerenciar resultados, como pode ser observado na Tabela 1.

Após a coleta, classificação e organização dos dados foram realizadas as regressões que objetivam explicar o nível de accruals discricionários nos anos $-1,0,+1,+2 \mathrm{e}+3$, calculados com base nos Modelos de Jones Modificado e de Performance-Matching. Ou seja, foram realizadas as regressões que possibilitam analisar quais os condicionantes para a prática do gerenciamento de resultados no contexto dos IPOs. Verificou-se pelo teste de Hausman que o modelo com efeitos fixos apresentou melhor ajustamento. Entretanto, verificou-se também que a regressão dos accruals discricionários calculados com base no Modelo de Jones Modificado apresentou problemas de autocorrelação e heterocedasticidade e a regressão com base no Modelo de Performance-Matching apresentou somente problemas relacionados a heterocedasticidade. Sendo assim, regressões para o modelo por Mínimos Quadrados Generalizados Factíveis (FGLS) assumindo ajustes de autocorrelação e heterocedasticidade para o Modelo de Jones Modificado e assumindo ajustes de heterocedasticidade para o Modelo de Performance-Matching foram realizadas.

Destarte, os resultados foram analisados objetivando inferir quais variáveis deste modelo se caracterizam como condicionantes para a prática do gerenciamento de resultados no contexto das ofertas públicas iniciais de empresas brasileiras que realizaram o IPO.

Tabela 2. Nível Médio de AD para as variáveis qualitativas do Modelo de Dados em Painel

\begin{tabular}{|c|c|c|c|c|c|c|}
\hline \multirow[b]{2}{*}{ Modelo } & \multirow[b]{2}{*}{ Variáveis } & \multicolumn{2}{|c|}{ Nível Médio de AD (em \% dos ATit -1) } & \multirow[b]{2}{*}{ Diferença } & \multirow[b]{2}{*}{$\operatorname{Prob}(T>t)$} & \multirow[b]{2}{*}{ Estat. $t$} \\
\hline & & $\begin{array}{l}\text { Dummy (1) } \\
\text { Presenca do } \\
\text { atributo }\end{array}$ & $\begin{array}{l}\text { Dummy (0) } \\
\frac{\text { Ausência do }}{\text { atributo }}\end{array}$ & & & \\
\hline \multirow{8}{*}{$\begin{array}{l}\text { Jones } \\
\text { Modificado }\end{array}$} & Fase IPO & $9.75 \%$ & $1.40 \%$ & $8.35 \%$ & $0.0000 *$ & 7.1284 \\
\hline & $P E V C$ & $4.44 \%$ & $7.06 \%$ & $-2.62 \%$ & $0.0163^{*}$ & -2.1385 \\
\hline & IFRS & $2.91 \%$ & $6.59 \%$ & $-3.68 \%$ & $0.0001 *$ & -3.7922 \\
\hline & $G C$ & $5.76 \%$ & $5.54 \%$ & $0.22 \%$ & 0.4437 & 0.1416 \\
\hline & $I S E$ & $1.91 \%$ & $6.13 \%$ & $-4.22 \%$ & $0.0001 *$ & -3.8514 \\
\hline & SEO & $6.73 \%$ & $5.53 \%$ & $1.20 \%$ & 0.2610 & 0.6410 \\
\hline & Auditor & $5.39 \%$ & $7.25 \%$ & $-1.86 \%$ & 0.1212 & -1.1694 \\
\hline & Quente & $12.33 \%$ & $2.08 \%$ & $10.25 \%$ & $0.0000 *$ & 6.4353 \\
\hline \multirow{8}{*}{$\begin{array}{l}\text { Performance } \\
\text { Matching }\end{array}$} & Fase IPO & $8.75 \%$ & $1.04 \%$ & $7.71 \%$ & $0.0000^{*}$ & 5.9530 \\
\hline & $P E V C$ & $3.07 \%$ & $7.08 \%$ & $-4.01 \%$ & $0.0011 *$ & -3.0544 \\
\hline & IFRS & $3.01 \%$ & $5.65 \%$ & $-2.64 \%$ & $0.0065^{*}$ & -2.4863 \\
\hline & $G C$ & $5.47 \%$ & $2.95 \%$ & $2.52 \%$ & $0.0725 * *$ & 1.4583 \\
\hline & $I S E$ & $-0.90 \%$ & $5.67 \%$ & $-6.57 \%$ & $0.0039 *$ & -2.6972 \\
\hline & SEO & $5.13 \%$ & $5.01 \%$ & $0.12 \%$ & 0.4755 & 0.0616 \\
\hline & Auditor & $4.58 \%$ & $7.10 \%$ & $-2.52 \%$ & $0.0469 *$ & -1.6791 \\
\hline & Quente & $10.21 \%$ & $2.17 \%$ & $8.04 \%$ & $0.0000 *$ & 4.6114 \\
\hline \multirow{6}{*}{$\begin{array}{l}\text { Variáveis } e \\
\text { significado }\end{array}$} & Fase IPO & \multicolumn{5}{|c|}{$\begin{array}{l}\text { Período chave para o IPO (Períodos próximos da oferta - Grandes incentivos para } \\
\text { GR). }\end{array}$} \\
\hline & $P E V C$ & \multicolumn{5}{|c|}{ Presença de Private Equity/Venture Capital - Gestores de capital de risco. } \\
\hline & IFRS & \multirow{2}{*}{\multicolumn{5}{|c|}{$\begin{array}{l}\text { Adoção às Normas Internacionais de Contabilidade - No Brasil, a partir de } 2010 . \\
\text { Governança Corporativa - Mecanismos de proteção do investidor. }\end{array}$}} \\
\hline & $G C$ & & & & & \\
\hline & $I S E$ & \multirow{2}{*}{\multicolumn{5}{|c|}{$\begin{array}{l}\text { Sustentabilidade Empresarial - Nível de transparência e prestação de contas. } \\
\text { Oferta Subsequente de Ações (Períodos que marcam a realização da oferta } \\
\text { secundária). }\end{array}$}} \\
\hline & SEO & & & & & \\
\hline
\end{tabular}




\begin{tabular}{ll}
\hline Auditor & Qualidade ou reputação da empresa de auditoria. \\
& Momento caracterizado pelo volume de ofertas públicas realizadas - "Quentes ou \\
Quente & Frios".
\end{tabular}

(*) e (**) Denota significância estatística ao nível de 5\% e 10\%, respectivamente.

Fonte: Resultados da Pesquisa.

Na Tabela 3 estão presentes os resultados do modelo pooled e também os resultados do modelo em painel com efeitos fixos estimados por FGLS. Neste contexto, destaque deve ser dado as variáveis Fase IPO, Quente, ISE, SEO, Crescimento, Desempenho, Capital de Giro, Tamanho e PIB que apresentaram sinal esperado e significância estatística tanto para a regressão do Modelo de Jones Modificado quanto para a regressão do Modelo de Performance-Matching. A variável Alavancagem para o Modelo de Performance-Matching e a variável IFRS para o Modelo de Jones Modificado também apresentaram significância estatística e sinal esperado.

Tabela 3. Condicionantes para a prática do Gerenciamento de Resultados Contábeis

\begin{tabular}{|c|c|c|c|c|c|}
\hline \multirow{3}{*}{$\begin{array}{l}\text { Variáveis/Modelo } \\
\text { Fase IPO }\end{array}$} & \multirow{3}{*}{$\begin{array}{c}\text { Sinal E. } \\
+\end{array}$} & \multicolumn{2}{|c|}{ Jones Modificado } & \multicolumn{2}{|c|}{ Performance-Matching } \\
\hline & & Pooled & Efeitos Fixos & Pooled & Efeitos Fixos \\
\hline & & 0.06919 & 0.06067 & 0.06230 & 0.04198 \\
\hline & & $(6,67)$ & $(8,74)$ & $(4,07)$ & $(6,58)$ \\
\hline & & $0.000 *$ & $0.000 *$ & $0.000 *$ & $0.000 *$ \\
\hline \multirow[t]{3}{*}{ IFRS } & $+/-$ & 0.00290 & -0.02261 & 0.0161067 & -0.01183 \\
\hline & & $(0,34)$ & $(-2,44)$ & $(1,68)$ & $(-1,62)$ \\
\hline & & 0.731 & $0.015 *$ & $0.092 * *$ & 0.105 \\
\hline \multirow[t]{3}{*}{ Quente } & + & 0.07258 & 0.04326 & 0.0450629 & 0.01776 \\
\hline & & $(5,40)$ & $(6,55)$ & $(2,73)$ & $(2,74)$ \\
\hline & & $0.000 *$ & $0.000 *$ & $0.006^{*}$ & $0.006 *$ \\
\hline \multirow[t]{3}{*}{ GC } & - & -0.00512 & 0.0850685 & 0.0208271 & 0.09409 \\
\hline & & $(-0,34)$ & $(1,73)$ & $(1,27)$ & $(1,71)$ \\
\hline & & 0.734 & $0.084 * *$ & 0.203 & $0.088 * *$ \\
\hline \multirow[t]{3}{*}{ ISE } & - & -0.07202 & -0.09095 & -0.0925495 & -0.28894 \\
\hline & & $(-5,10)$ & $(-1,67)$ & $(-3,08)$ & $(-1,72)$ \\
\hline & & $0.000 *$ & $0.095 * *$ & $0.002 *$ & $0.086 * *$ \\
\hline \multirow[t]{3}{*}{ SEO } & + & 0.03240 & 1.10078 & 0.0276347 & 0.96885 \\
\hline & & $(1,53)$ & $(38,04)$ & $(1,28)$ & $(33,20)$ \\
\hline & & 0.125 & $0.000 *$ & 0.202 & $0.000 *$ \\
\hline \multirow[t]{3}{*}{ PEVC } & $+/-$ & -0.03143 & 0.04458 & -0.0445554 & -0.05894 \\
\hline & & $(-2,54)$ & $(0,45)$ & $(-3,55)$ & $(-0,40)$ \\
\hline & & $0.011 *$ & 0.653 & $0.000 *$ & 0.689 \\
\hline \multirow[t]{3}{*}{ Auditor } & - & -0.02352 & -0.04391 & -0.0165521 & 0.05629 \\
\hline & & $(-1,66)$ & $(-0,47)$ & $(-1,23)$ & $(0,40)$ \\
\hline & & $0.096 * *$ & 0.636 & 0.217 & 0.686 \\
\hline \multirow[t]{3}{*}{ Crescimento } & + & 0.03689 & 0.02031 & 0.0494705 & 0.01687 \\
\hline & & $(3,32)$ & $(5,49)$ & $(2,99)$ & $(4,78)$ \\
\hline & & $0.001 *$ & $0.000 *$ & $0.003 *$ & $0.000 *$ \\
\hline \multirow[t]{3}{*}{ Desempenho } & $+/-$ & 0.00759 & 0.00506 & 0.0080403 & 0.00738 \\
\hline & & $(4,77)$ & $(7,04)$ & $(3,77)$ & $(11,11)$ \\
\hline & & $0.000 *$ & $0.000 *$ & $0.000 *$ & $0.000 *$ \\
\hline \multirow[t]{3}{*}{ Tangibilidade } & + & $-2.19 \mathrm{E}-06$ & -1.10E-06 & $-9.50 \mathrm{E}-07$ & -8.71E-07 \\
\hline & & $(-3,70)$ & $(-0,77)$ & $(-1,39)$ & $(-0,75)$ \\
\hline & & $0.000 *$ & 0.439 & 0.163 & 0.451 \\
\hline \multirow[t]{3}{*}{ Alavancagem } & $+/-$ & -0.04495 & 0.03027 & -0.0136911 & 0.04446 \\
\hline & & $(-1,56)$ & $(1,37)$ & $(-0,46)$ & $(2,33)$ \\
\hline & & 0.120 & 0.170 & 0.646 & $0.020 *$ \\
\hline \multirow[t]{3}{*}{ Capital de Giro } & $+/-$ & $2.43 \mathrm{E}-10$ & $1.30 E-10$ & $3.08 \mathrm{E}-10$ & $4.20 E-10$ \\
\hline & & $(2,65)$ & $(5,73)$ & $(4,24)$ & $(24,70)$ \\
\hline & & $0.008 *$ & $0.000 *$ & $0.000^{*}$ & $0.000 *$ \\
\hline \multirow[t]{2}{*}{ Tamanho } & $+/-$ & 0.12168 & 0.17755 & 0.0837491 & 0.09885 \\
\hline & & $(6,71)$ & $(16,39)$ & $(3,47)$ & $(8,28)$ \\
\hline
\end{tabular}




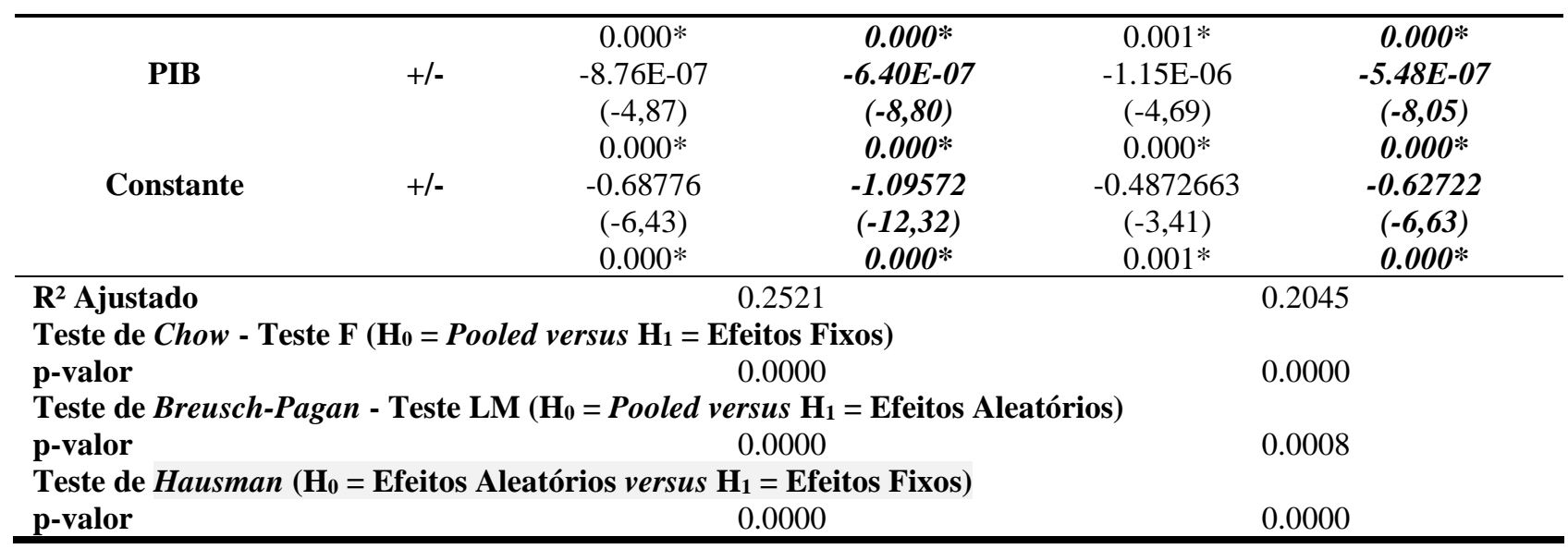

(*) e (**) Denota significância estatística ao nível de $5 \%$ e $10 \%$, respectivamente.

Fonte: Resultados da Pesquisa.

O intuito foi verificar se, de fato, existem condicionantes para a prática do gerenciamento de resultados no contexto dos IPOs. Para isso, utilizou-se os níveis de accruals discricionários ponderados pelo ativo total do período anterior para cada empresa nos anos -1 e 0 , calculados com base nos Modelos de Jones Modificado (1995) e de Performance-Matching (2005) como variável dependente/explicada. Cabe destacar que estes accruals discricionários foram apurados trimestralmente nos anos -1 e 0, para cada empresa da amostra formando um painel de observações.

Quanto às variáveis explicativas não existe um consenso literário sobre quais possuem maiores efeitos para explicar o nível de accruals discricionários das empresas. Entretanto, variáveis qualitativas (Fase IPO; IFRS; Quente; GC; ISE; SEO; PEVC e Auditor) e quantitativas (Crescimento; Desempenho; Tangibilidade; Alavancagem; Capital de Giro; Tamanho e PIB) foram inseridas no modelo de regressão por se caracterizarem como as mais comuns variáveis que vêm sendo utilizadas por autores nacionais e internacionais (Cupertino, Martinez e Costa Jr. (2014), Dechow, Sloan e Sweeney (1995), Ye (2006), McNichols (2000), Baptista (2008), Kothari, Leone e Wasley (2005), Castro (2008), Zang (2012), Teoh, Welch e Wong (1998), Hochberg (2011), Martinez (2001), Morsfield e Tan (2006), Ronen e Yaari (2008), Gioielli, Carvalho e Sampaio (2013) e Fasolin e Klann (2014) como condicionantes do gerenciamento de resultados contábeis.

Neste contexto, destaque deve ser dado as variáveis Fase IPO, Quente, ISE, SEO, Crescimento, Desempenho, Capital de Giro, Tamanho e PIB que apresentaram sinal esperado e significância estatística para as regressões dos Modelos de Jones Modificado e de PerformanceMatching. A variável Alavancagem para o Modelo de Performance-Matching e a variável IFRS para o Modelo de Jones Modificado também apresentaram significância estatística e sinal esperado.

A Fase IPO se caracteriza como uma variável dummy que assume o valor um para as 11 observações (trimestres) do período chave, o período que antecede, marca e imediatamente posterior ao IPO (ano-1, anoo e ano+1) para a empresa $i$, e zero, caso contrário.

Gioielli, Carvalho e Sampaio (2013) enfatizam que no período chave para o IPO (período que antecede imediatamente a oferta) o incentivo dos gestores para manipular os resultados para maior é muito forte. Martinez (2001) também enfatiza que há incentivos para gerenciar resultados por parte das empresas IPO, assim como Teoh, Welch e Wong (1998) que elucidam que assim como nos períodos imediatamente anteriores (início de formação dos accruals), o período que marca (inflacionar o preço das ações) e imediatamente posterior (evitar processos judiciais; período de lockup - período de restrição de venda dos papéis dos administradores), também são caracterizados pelos altos incentivos dos gestores para gerenciar resultados.

Portanto, era esperado que o coeficiente desta variável responsável por captar as observações da empresa $i$ no período crítico para o IPO fosse positivo, indicando que nos trimestres referentes aos anos $(-1,0$ e +1$)$ os níveis de accruals discricionários seriam maiores do que em períodos posteriores, dado que os incentivos para gerenciar resultados diminuem consideravelmente. 
Neste contexto, corroborando com os autores mencionados e com os resultados esperados para esta variável a variável Fase IPO responsável por captar o comportamento do nível de accruals discricionários no período crítico para o IPO elucida indícios de que os incentivos para gerenciar resultados são fortes nos períodos prévios do evento do IPO.

A variável Quente se caracteriza como uma variável dummy que assume o valor um quando a observação vem de um trimestre caracterizado como "quente", e zero, caso contrário. Os trimestres foram denominados "quentes e frios" em função do volume de IPOs realizados em cada um dos trimestres analisados. Assim, foram considerados "quentes" os trimestres com número de ofertas superior a média apresentada em todo o período analisado e "frios" os trimestres com número de ofertas inferior a esta média. Esta definição é suportada por autores como Alti (2006), Rossi Jr. e Marotta (2010) e Baker e Wurgler (2002).

A definição implica que se houver uma percepção por parte dos gestores de que há uma janela de oportunidade, onde o custo de capital via ações está baixo, relativamente a outras modalidades de financiamento, haverá uma concentração natural de IPOs nesse período e uma tendência dos gestores em ofertar volume maior de ações para aproveitar o momento percebido como favorável.

Neste contexto, estes "momentos quentes", podem também ser favoráveis para a prática do gerenciamento de resultados contábeis por parte dos gestores dado que usufruindo destas janelas de oportunidade os gestores podem abastecer o mercado com expectativas falsas, fruto do gerenciamento de resultados contábeis.

Portanto, era esperado encontrar sinal positivo para esta variável corroborando com as expectativas relacionadas às janelas de oportunidade, momentos caracterizados como quentes, de economia aquecida. De acordo com os resultados esperados para esta variável, foi verificado que a variável Quente se mostrou significativa ao nível de significância de $1 \%$ e apresentou sinal positivo, corroborando com os resultados esperados e sinalizando indícios de que em momentos caracterizados comoquentes, com elevado volume de ofertas públicas de ações, as empresas IPO apresentam maiores níveis de acumulações discricionárias aproveitando das janelas de oportunidade.

Hochberg (2011) salienta que empresas com maiores taxas de crescimento estão mais propensas a gerenciar seus resultados e, consecutivamente, apresentar maiores níveis de accruals discricionários uma vez que estão em corrente expansão, utilizando-se de algum grau de imprecisão dos números relatados. Baptista (2008) elucida que maiores níveis de accruals podem estar relacionados a maiores expectativas de crescimento. Fasolin e Klann (2014) também esperam um sinal positivo para esta variável, ou seja, empresas em crescimento apresentariam maiores níveis de acumulações discricionárias.

Corroborando com os resultados mencionados pelos autores e apontados na hipótese desta pesquisa, a variável Crescimento apresentou sinal positivo e estatística $t$ com significância estatística ao nível de $1 \%$ em duas regressões.

Ronen e Yaari (2008) assim como Martinez (2001) elucidam que a adoção de mecanismos de Governança Corporativa se caracteriza como fatores limitadores para a prática do gerenciamento de resultados contábeis. Baptista (2008) encontrou relação negativa entre o nível de governança e o nível de accruals discricionários das empresas. Mecanismos que protejam os interesses dos investidores irão objetivar mitigar o gerenciamento de resultados que pode distorcer as avaliações realizadas por investidores existentes e em potencial.

Assim sendo, era esperado que o coeficiente encontrado para esta variável seja negativo indicando que quando da presença de mecanismos de governança corporativa, há menor nível de acumulações discricionárias assumidas pelas empresas.

Entretanto, os resultados sinalizam indícios de que para as empresas estudadas na amostra, a presença no Novo Mercado com mecanismos de governança corporativa não estaria relacionada com menores níveis de accruals discricionários. Cabe destacar que estes resultados não corroboram com os resultados esperados nesta pesquisa. 
Assim como para a Governança Corporativa, Ronen e Yaari (2008) elucidam que a Sustentabilidade Empresarial também se caracteriza como fator limitador para a prática do gerenciamento de resultados contábeis. Empresas sustentáveis estão comprometidas e diferenciamse em termos de qualidade, nível de compromisso com o desenvolvimento sustentável, equidade, transparência e prestação de contas (BM\&FBOVESPA, 2014).

Assim sendo, era esperado que o coeficiente encontrado para esta variável fosse negativo indicando que empresas sustentáveis empresarialmente apresentam menor nível de acumulações discricionárias. Neste contexto, o resultado encontrado sinaliza indícios de que as empresas estudadas sustentáveis com maiores níveis de transparência, equidade e prestação de contas (presentes no ISE - Índice de Sustentabilidade Empresarial) apresentam menores níveis de accruals discricionários, corroborando com os resultados esperados.

De maneira geral os resultados apresentados para as variáveis estão em consonância com os resultados esperados na hipótese desta pesquisa. Cabe destacar que, somente a variável GC apresentou significância estatística e resultado inesperado que não corrobora com os resultados apontados na hipótese. Enfim, as variáveis estatisticamente significativas apresentaram indícios para maiores ou menores níveis de accruals discricionárias. Ou seja, há indícios de que estas variáveis (Fase IPO, Quente, ISE, SEO, GC, Crescimento, Desempenho, Capital de Giro, Tamanho e PIB) se caracterizam como condicionantes do gerenciamento no contexto dos IPOs.

\section{CONSIDERAÇÕES FINAIS}

Observou-se que os níveis de acumulações discricionárias nos períodos imediatamente ao redor do evento do IPO (anos -1, 0 e +1) são maiores do que os níveis apurados nos períodos posteriores ao evento. Este padrão foi confirmado pelo teste $t$ para a diferença de médias que apontou que os níveis médios de accruals discricionários são maiores e distintos estatisticamente para os anos $-1,0$ e +1 se comparados com os níveis médios apurados para os anos +2 e +3 . Para a amostra analisada na presente pesquisa, após os testes estatísticos realizados, foram obtidas evidências de que as empresas brasileiras que realizaram IPO no período estudado apresentaram maiores níveis de accruals discricionários nos anos que antecederam o IPO, ou seja, há evidências de prática de gerenciamento de resultados para maior antes do lançamento de novas ações no mercado.

Quanto à avaliação dos condicionantes para a prática do gerenciamento de resultados cabe destacar que é de suma importância analisar quais seriam os condicionantes para a prática do gerenciamento de resultados. Neste sentido, optou-se por acrescentar ao estudo uma análise de regressão com dados em painel onde se puderam avaliar as variáveis, de acordo com a literatura nacional e internacional acerca do tema, que explicam a ocorrência desse fenômeno Há indícios de que as variáveis: Fase do IPO; Momento "Quente" do mercado; Sustentabilidade Empresarial (ISE); SEO; Governança Corporativa; Crescimento da Firma; Desempenho recente; Capital de Giro, Tamanho da firma e o comportamento da economia (PIB) se caracterizam como condicionantes do gerenciamento de resultados contábeis no contexto dos IPOs recentes no Brasil.

Como sugestões para futuras pesquisas a respeito do tema aqui tratado, sugere-se buscar evidências de gerenciamento de resultados em ofertas públicas iniciais de ações por meio de outras metodologias alternativas, por exemplo, por meio da análise de variáveis que reflitam outras mudanças contábeis, como por exemplo, as estimativas de valores residuais de ativos, estimativas de perdas para créditos de liquidação duvidosa. Outra proposta seria a de verificar se, no longo prazo, existem diferenças significativas no comportamento dos preços, dos retornos e dos riscos das ações de empresas que possivelmente gerenciaram seus resultados contábeis em períodos próximos ao IPO comparando as com os resultados de outras firmas similares em termos de setor de atividade e porte, mas que já possuíam capital aberto na B3. 


\section{REFERÊNCIAS}

Aldrighi, D. M., Afonso, L. E., Capparelli, G., \& Santos, A. (2010). As ofertas públicas iniciais na Bovespa no período recente: características das empresas, estrutura de propriedade e de controle, e desempenho. XXXVIII Encontro Nacional de Economia-ANPEC, Salvador.

Alhadab, M., Clacher, I. \& Keasey, K. (2013). Real and Accrual Earnings Management and IPO Failure Risk. Fev. Disponível em: SSRN: http://ssrn.com/abstract=2225411.

Alti, A. (2006). How persistent is the impact of market timing on capital structure?. The Journal of Finance, 61(4), 1681-1710.

Baltagi, B. \& Boozer, M. (2009). Econometric analysis of panel data. New York: John Wiley \& Sons.

Baptista, E. M. B. (2008). Análise do perfil das empresas brasileiras segundo o nível de gerenciamento de resultados (Tese de Doutorado). Universidade Federal do Rio Grande do Sul, Programa de Pós Graduação em Administração, Porto Alegre.

Berk, J. \& Demarzo, P. (2009). Finanças Empresariais. Tradução: Christiane de Brito Andrei. Porto Alegre: Bookman.

Bispo, O. N. A. (2010). Gerenciamento de Resultados Contábeis e o Desempenho das Ofertas Públicas Subsequentes de Ações em Empresas Brasileiras. (Dissertação de Mestrado) Faculdade de Ciências Econômicas, Universidade Federal de Minas Gerais, Belo Horizonte.

BM\&FBovespa, 2014. Ofertas Públicas de Distribuição de Ações. Disponível em: http://www.bmfbovespa.com.br/pt-br/mercados/acoes/ofertas-publicas/ofertaspublicas.aspx? idioma=pt-br. Acesso em: 03.01.2014.

Carvalho, A. G., Pinheiro, R. B., \& Sampaio, J. O. (2020). The dynamics of earnings management in IPOs and the role of venture capital. Research in International Business and Finance, 51, 101084.

Cupertino, C. M., Martinez, A. L. \& Costa Jr., N. C. A. (2014). Estratégias de Gerenciamento de Resultados: Custos Determinantes e Sequencialidade. XXXVIII EnANPAD 2014. Rio de Janeiro.

Dechow, P. M., Sloan, R. G., \& Sweeney, A. P. (1995). Detecting earnings management. The Accounting Review, 193-225.

Elbannan, M. A. (2011). Accounting and stock market effects of international accounting standards adoption in an emerging economy. Review of Quantitative Finance and Accounting, 36(2), 207-245.

Elston, J. A., \& Yang, J. J. (2010). Venture capital, ownership structure, accounting standards and IPO underpricing: Evidence from Germany. Journal of Economics and Business, 62(6), 517-536.

Espenlaub, S., Garrett, I., \& Mun, W. P. (1999). Conflicts of interest and the performance of venture-capitalbacked IPOs: a preliminary look at the UK. Venture Capital: An International Journal of Entrepreneurial Finance, 1(4), 325-349.

Fasolin, L. B. \& Klann, R. C. (2014). Gerenciamento de Resultados por meio da venda de ativos fixos. VIII Congresso Anpcont, Rio de Janeiro.

Gioiellii, S. P. O., de Carvalho, A. G., \& Sampaio, J. O. (2013). Capital de risco e gerenciamento de resultados em IPOs. BBR-Brazilian Business Review, 10(4), 32-68.

Gujarati, D. N. \& Porter, D. C. (2011). Econometria Básica. 5 ed. Porto Alegre: AMGH.

Healy, P. M., \& Wahlen, J. M. (1999). A review of the earnings management literature and its implications for standard setting. Accounting Horizons, 13(4), 365-383.

Hochberg, Y. V. (2012). Venture capital and corporate governance in the newly public firm. Review of Finance, 16(2), 429-480.

Jeanjean, T., \& Stolowy, H. (2008). Do accounting standards matter? An exploratory analysis of earnings management before and after IFRS adoption. Journal of Accounting and Public Policy, 27(6), 480494.

Khurshed, A., Paleari, S., Pande, A., \& Vismara, S. (2014). Transparent bookbuilding, certification and initial public offerings. Journal of Financial Markets, 19, 154-169.

Kothari, S. P., Leone, A. J., \& Wasley, C. E. (2005). Performance matched discretionary accrual measures. Journal of Accounting and Economics, 39(1), 163-197.

Lin, Z. J., \& Tian, Z. (2012). Accounting conservatism and IPO underpricing: China evidence. Journal of International Accounting, Auditing and Taxation, 21(2), 127-144.

Martinez, A. L. (2001). "Gerenciamento" dos Resultados Contábeis: estudo empírico das companhias abertas brasileiras (Tese de Doutorado). Faculdade de Economia, Administração e Contabilidade da Universidade de São Paulo, São Paulo. 
Morsfield, S. G., \& Tan, C. E. (2006). Do venture capitalists influence the decision to manage earnings in initial public offerings?. The Accounting Review, 81(5), 1119-1150.

Nakamura, W. T., Forte, D. \& Aguiar, J. F. (2006). Análise do Processo Decisório dos Gestores de Capital de Risco no Brasil. $30^{\circ}$ Encontro da ANPAD - EnANPAD 2006. Salvador.

Paulo, E. (2006). Gerenciamento de resultados e a oferta pública de ações pelas companhias abertas brasileiras. $30^{\circ}$ Encontro da ANPAD - EnANPAD 2006, Salvador.

Rangan, S. (1998). Earnings management and the performance of seasoned equity offerings. Journal of Financial Economics, 50(1), 101-122.

Ronen, J. \& Yaari, V. (2008). Earnings Management: emerging insights in theory, practice, and research. Springer Series in Accounting Scholarship, New York: Springer.

Roosenboom, P., van der Goot, T., \& Mertens, G. (2003). Earnings management and initial public offerings: Evidence from the Netherlands. The International Journal of Accounting, 38(3), 243-266.

Teoh, S. H., Welch, I., \& Wong, T. J. (1998). Earnings management and the long-run market performance of initial public offerings. The Journal of Finance, 53(6), 1935-1974.

Teoh, S. H., Wong, T. J., \& Rao, G. R. (1998). Are accruals during initial public offerings opportunistic?. Review of Accounting Studies, 3(1-2), 175-208.

Watts, R. L., \& Zimmerman, J. L. (1978). Towards a positive theory of the determination of accounting standards. The Accounting Review, 112-134.

Ye, J. (2006). Accounting Accruals and Tests of Earnings Management. Working Paper, Baruch College. 